RECISATEC - REVISTA CIENTÍFICA SAÚDE E TECNOLOGIA ISSN 2763-8405

\title{
O PRÉ-NATAL: O OLHAR DE MULHERES GRÁVIDAS AOS CUIDADOS RECEBIDOS PELA EQUIPE DE SAÚDE
}

\section{PRENATAL: THE VIEW OF PREGNANT WOMEN TO THE CARE RECEIVED BY THE HEALTH TEAM}

Janaina Alvarenga Aragão¹, José Roque Junges², Luciano Silva Figueiredo³, Verônica Lourdes Lima Batista $\mathrm{Maia}^{4}$, Maria Conceição Portela Leal Macedo ${ }^{5}$, Socorro Adriana Sousa Meneses Brandão ${ }^{6}$, Leilane Sousa Dias ${ }^{7}$, Rita de Kássia Leal e Silva ${ }^{8}$

\section{RESUMO}

Identificar a percepção das mães sobre a atuação dos profissionais de saúde no pré-natal de uma unidade básica de saúde; conhecer a percepção das mães sobre as orientações recebidas na unidade básica de saúde durante o pré-natal; conhecer a percepção das mães sobre a preparação do parto orientado pelos profissionais de saúde. Metodologia qualitativa-descritiva, com dados coletados de maio a agosto/2009, por meio de entrevistas semiestruturadas com doze mulheres grávidas durante o puerpério que realizaram pré-natal no Posto de Saúde Materno Infantil, São Leopoldo-RS. A análise dos dados realizou-se pela análise de conteúdo. A maioria das participantes considerou que, dentre os profissionais que devem realizar o pré-natal, o médico é o principal. As abordagens educativas mais discutidas, data provável de parto, peso gestacional, consulta puerperal e a amamentação, ficaram em segundo plano. É fundamental rediscutir a assistência pré-natal na atenção básica e a maneira como vem ocorrendo a interação dessas políticas, tendo como ponto de partida a percepção das usuárias do pré-natal, pois esse novo enfoque pode efetivar a assistência integral e humanizada.

PALAVRAS-CHAVE: Gravidez. Política de Saúde. Humanização da Assistência.

\begin{abstract}
Identifying the perception of mothers about the work of health professionals of a basic health unit (public health clinic) in the pre-natal period; getting to know the perception of mothers about the guidance received at the public health clinic during the pre-natal period; getting to know the perception of mothers about the preparation for birth oriented by health professionals. Methodology qualitativedescriptive, collecting data from May to August 2009, through semi-structured interviews with twelve pregnant women during their pregnancy, who were being assisted in their pre-natal period at the Public Health Clinic for Mothers and Children in São Leopoldo, Rio Grande do Sul State, Southern Brazil. The analysis of data was carried out through the analysis of content. The majority of participants have considered that among the professionals who should be performing the work of assisting them, the doctor was the most important person. The most discussed educational approaches were: placental abruption, gestational weight, and postnatal consultations; breastfeeding was relegated to a secondary level in their preoccupations. Therefore, it is extremely important to rediscuss pre-natal assistance at public health units (clinics), and the manner in which it has been carried out so far, as well as the interaction between those practices and public health policies. The
\end{abstract}

\footnotetext{
1 Universidade Estadual do Piauí

2 Universidade do Vale do Rio dos Sinos

3 Universidade Estadual do Piauí

4 Universidade Estadual do Piauí

5 Universidade Estadual do Piauí

6 Universidade Estadual do Piauí

7 Universidade Estadual do Piauí

8 Universidade Estadual do Piauí
} 


\title{
RECISATEC - REVISTA CIENTÍFICA SAÚDE E TECNOLOGIA ISSN 2763-8405
}

\author{
O PRÉ-NATAL: O OLHAR DE MULHERES GRÁVIDAS AOS CUIDADOS RECEBIDOS PELA EQUIPE DE SAÚDE \\ Janaina Alvarenga Aragão, José Roque Junges, Luciano Silva Figueiredo, Verônica Lourdes Lima Batista Maia, \\ Maria Conceição Portela Leal Macedo, Socorro Adriana Sousa Meneses Brandão, Leilane Sousa Dias, Rita de Kássia Leal e Silva
}

perception of users in relation to the work of pre-natal assistance should be adopted as a departure point in those discussions, as this approach may bring to effect an integral, humanized assistance.

KEYWORDS: Pregnancy. Humanization of Assistance. Humanization of Assistance.

\section{INTRODUÇÃO}

A gravidez é um evento fisiológico com mudanças físicas e emocionais diferenciadas em cada mulher, podendo gerar medo, ansiedade, dúvidas, fantasias ou a curiosidade de entender como o corpo está se desenvolvendo. É uma fase onde a mulher necessita de cuidados do companheiro, familiares e profissionais de saúde para além das práticas curativas, ou seja, atendimento integral e humanizado. ${ }^{(1,2)}$

Este evento na vida da mulher é delicado, por isso necessita de zelo e perícia por parte de todos os profissionais de saúde, que devem aumentar a responsabilidade por sua prática, gerando mudanças sensíveis e humanas nas atividades diárias de assistência à mulher. A qualidade no atendimento durante o pré-natal, parto e puerpério não depende só da instituição de saúde. ${ }^{(1,3)}$

Trabalhos avaliando programas públicos de saúde na ótica dos usuários que utilizam a atenção pré-natal, ainda não são comuns na literatura técnica e científica brasileira. ${ }^{(4,5)}$ Entretanto, internacionalmente são realizados alguns estudos, como nos países industrializados, onde a atenção à saúde é mais provida de recursos financeiros em comparação aos países de baixa renda. Os países mais ricos costumam ressaltar o comportamento de clientelas de baixa renda, em que entrevistaram mulheres de baixa renda nos EUA, comparando duas amostras com 125 beneficiárias do Medicaid (assistência à saúde voltada à população pobre) e com 275 não vinculadas ao programa e obtiveram altas taxas de aprovação. Cumpre destacar que a aprovação entre as beneficiárias do Medicaid foi comparativamente maior, apesar de este grupo registrar um número médio de consultas menor. ${ }^{(6)}$

A presente pesquisa deseja fortalecer o respeito e a autonomia de todos os componentes desse universo, e acima de tudo, destacar a importância do empoderamento das usuárias nos processos de planejamento e tomada de decisões que cercam sua vida, fato assegurado pela Lei oㅡ 8.080/90 e 8.142/90 do SUS (Sistema Único de Saúde). ${ }^{(7-9)}$ Nesse sentido, o presente estudo tem por objetivo identificar a percepção das mães sobre a atuação dos profissionais de saúde no pré-natal de uma unidade básica de saúde; conhecer a percepção das mães sobre as orientações recebidas na unidade básica de saúde durante o pré-natal; e conhecer a percepção das mães sobre a preparação do parto orientado pelos profissionais de saúde.

\section{MÉTODOS}

Trata-se de uma pesquisa qualitativo-descritiva, trabalhando interpretações baseadas em realidades sociais, focalizando opiniões sobre um determinado fato, para entender as diversas posições tomadas pelos indivíduos sociais. ${ }^{(10)}$ 


\section{RECISATEC - REVISTA CIENTÍFICA SAÚDE E TECNOLOGIA ISSN 2763-8405}

\section{O PRÉ-NATAL: O OLHAR DE MULHERES GRÁVIDAS AOS CUIDADOS RECEBIDOS PELA EQUIPE DE SAÚDE Janaina Alvarenga Aragão, José Roque Junges, Luciano Silva Figueiredo, Verônica Lourdes Lima Batista Maia, Maria Conceição Portela Leal Macedo, Socorro Adriana Sousa Meneses Brandão, Leilane Sousa Dias, Rita de Kássia Leal e Silva}

A amostra do estudo foi composta por doze puérperas1 que realizaram pré-natal de baixo risco no Posto de Saúde Materno-Infantil, São Leopoldo-RS. A assistência pré-natal foi escolhida por ser um bom indicativo de qualidade em saúde, de ampla distribuição nacional e relevância na totalidade da atenção básica. Seu nível de cobertura é considerado um dos principais indicadores do Pacto da Atenção Básica do SUS. ${ }^{(6)}$ A seleção das entrevistadas baseou-se nos seguintes critérios: mulheres inscritas no pré-natal com diagnóstico confirmado de gravidez através de exame clínico e laboratorial, maiores de dezenove anos, devido à gravidez na adolescência ser outra temática em particular. ${ }^{(1)}$ Mulheres alfabetizadas e residentes em São Leopoldo-RS e alfabetizadas.

Os dados coletados através de entrevistas pré-agendadas, e gravadas pela própria pesquisadora, realizadas no local de preferência da puérpera durante o puerpério, contemplando questões relacionadas à percepção do pré-natal, à preparação para o parto e aos sujeitos envolvidos. As entrevistas são diálogos entre duas pessoas, uma interação e troca de pensamentos e significados da realidade explorada. ${ }^{(11,12)}$

A interpretação do material ocorreu através da análise de conteúdo, segundo recomendações de $\operatorname{Bardin}^{(13)}$ dividida em três fases: pré-análise, exploração do material e tratamento dos resultados, inferência e interpretação.

A pesquisa foi avaliada e aprovada pelo Comitê de Ética da Universidade do Vale do Rio dos Sinos, resolução no: 045/2009. As entrevistas gravadas foram posteriormente transcritas na íntegra com consentimento das participantes identificadas por letras do alfabeto. Para a divulgação científica foi garantida a privacidade e a confidencialidade dos dados coletados pelo anonimato das entrevistadas.

Para a caracterização do contexto cotidiano das puérperas que participaram da pesquisa, destaca-se que oito estavam na faixa etária de 20 e 29 anos e quatro, de 30 a 39 anos. Quanto à escolaridade três tinham o primeiro grau incompleto e três, completo, uma com o segundo grau incompleto e quatro com o segundo completo, e uma cursava o terceiro grau. Das participantes, dez disseram ser casadas, uma solteira e outra em união estável. Em relação ao número de filhos, a média foi aproximada, seis puérpera com dois filhos e cinco com um filho, somente a solteira possuía mais de dois filhos. A maioria das entrevistadas, dez, relataram morarem com cônjuge e filho(s).

\section{RESULTADOS}

Durante a leitura da análise dos dados, vislumbrou-se a convergência das falas na direção da construção de três grandes categorias: onipresença do médico, conteúdos das abordagens educativas de preparação das gestantes e, por último, as relações, os aspectos emocionais e mudanças nos vínculos afetivos - interação entre profissionais e gestantes. Estas questões serão apresentadas e discutidas a seguir sob a ótica da literatura científica que aborda as questões referentes à integralidade e ao Programa de Humanização no Pré-Natal e Nascimento. 


\section{Onipresença do médico}

O PRÉ-NATAL: O OLHAR DE MULHERES GRÁVIDAS AOS CUIDADOS RECEBIDOS PELA EQUIPE DE SAÚDE Janaina Alvarenga Aragão, José Roque Junges, Luciano Silva Figueiredo, Verônica Lourdes Lima Batista Maia, Maria Conceição Portela Leal Macedo, Socorro Adriana Sousa Meneses Brandão, Leilane Sousa Dias, Rita de Kássia Leal e Silva

Esta categoria refere-se ao que as puérperas achavam do acompanhamento pré-natal, quem fazia as consultas, o modo como aconteciam, e na opinião delas, sobre qual profissional deveria realizá-la.

Quanto ao acompanhamento da gestação, a assistência foi considerada ótima e muito boa na opinião das mulheres: Ah! foi maravilhoso (...) (G). Foi tudo ótimo. Foi tudo tranquilo assim, bem tranquilo $(H)$.

A respeito do início do pré-natal, nove entrevistadas responderam que começaram no primeiro trimestre, contrariando o que relata Pereira et al.(14) Em relação à quantidade, oito puérperas realizaram seis ou mais consultas de pré-natal, portanto a média de consultas de cada uma confirma o aumento deste indicador no Brasil. ${ }^{(1)}$

Observou-se que oito das participantes considerou imprescindível o médico como profissional ideal para acompanhar a gestação. Fato expressado na fala da entrevistada J: Acho que só o meu médico. É, é o suficiente, ele é que vai dizer tudinho, e eu fui bem orientada por ele.

Mesmo o estudo tendo encontrado essa premissa, ocorreu a compreensão de que ele deve estar sempre qualificado, buscando aperfeiçoamento contínuo, como afirma a entrevistada $\mathrm{F}$ : $E u$ acho que tem que continuar os mesmos, só que tem que reciclar os médicos. A entrevistada $G$ foi além, percebeu a importância de o profissional sentir a vocação para o cuidado no seu verdadeiro sentido, algo tão importante quanto a técnica. ${ }^{(15)} \mathrm{O}$ medico, né, com qualificação, né, que ama o que faz (...), que trate bem a gestante, faz tudo direitinho (...).

Algumas puérperas também demonstraram a percepção mesmo que diminuta sobre a necessidade de agregar outros profissionais para complementar a assistência recebida: (...) Como foi realizado comigo, é o médico e a nutricionista, né? Acho que isso dá (L). Entretanto, a entrevistada $\mathrm{A}$ foi redundante ao indicar a necessidade de outro profissional (o pediatra) para integrar a equipe, pois este pertence a mesma categoria médica: (...) Eu acho assim, até seria bom a gente ter um contato com o pediatra também, pra (...) se preparar bem. (...) o pediatra pode passar pra ti porque ele entende de criança (...) ao menos assim nos últimos três meses, não no pré-natal todo.

A importância da introdução de outros profissionais durante a assistência oferecida foi constatada, porém se notou a falta de indicação de um importante profissional que deve compor o corpo de profissionais durante a assistência à saúde da mulher, como relata a entrevistada B: (...) Ótima, todos atenciosos, aquela que tava conversando aqui comigo, ela sempre atenciosa. Aqui não tem enfermeira né?

Mesmo a gestante percebendo a importância de agregar outros profissionais durante o prénatal, nas palavras a seguir algumas ainda demonstraram o desconhecimento sobre as atividades e contribuições que outros profissionais podem somar ao cuidado, e a divisão de competências técnicas que devem ser compartilhadas entre os membros da equipe: (...) Obstetra. É, porque né, eu só consultei com ele, (...), daí não sei como seria as outras funções das outras pessoas (H). 


\title{
RECISATEC - REVISTA CIENTÍFICA SAÚDE E TECNOLOGIA ISSN 2763-8405
}

\author{
O PRÉ-NATAL: O OLHAR DE MULHERES GRÁVIDAS AOS CUIDADOS RECEBIDOS PELA EQUIPE DE SAÚDE \\ Janaina Alvarenga Aragão, José Roque Junges, Luciano Silva Figueiredo, Verônica Lourdes Lima Batista Maia, \\ Maria Conceição Portela Leal Macedo, Socorro Adriana Sousa Meneses Brandão, Leilane Sousa Dias, Rita de Kássia Leal e Silva
}

Percebeu-se mais um agravo pelos depoimentos, a falta de compreensão sobre a especialidade médica mais adequada para o atendimento à gestante, se deve ser o obstetra ou 0 ginecologista: Acho que ele mesmo, o ginecologista acho. (B).

\section{Conteúdos das abordagens educativas de preparação das gestantes}

Nesta categoria as falas foram utilizadas para ilustrar os temas mais abordados durante as consultas, para notar o modo como os profissionais preparavam as gestantes para o pré-natal, parto e pós-parto, bem como perceber a importância da inserção natural das temáticas peculiares às etapas do ciclo gravídico-puerperal e a necessidade de ter recebido outras orientações, que porventura, não tenham sido discutidas durante as consultas.

Inicialmente, quanto ao modo como as orientações eram transmitidas oito das entrevistadas as consideraram boas, duas (normais), uma delas as classificou como ótimas, e outra, como adequadas.

Como se sabe, é importante avaliar os temas que são mais abordados durante uma consulta pré-natal. Eles devem ser utilizados durante o acompanhamento da gestante devido às significativas transformações obstétricas. Essa prática executada adequadamente confere maior proteção contra eventualidades futuras.

Através da fala das entrevistadas constatou-se a preocupação do médico com as intercorrências ginecológicas mais comuns durante a gravidez. É importante exemplificar este aspecto com o depoimento da entrevistada D, secundípara de 30 anos, cursando o terceiro grau, que, apesar dos desacertos, demonstra o apreço à prevenção, promoção e proteção à saúde da mulher grávida: Normalmente, a gente sabe que não pode consumir bebida alcoólica em excesso, né, (...) não pode fazer muito esforço físico, não pode pegar peso, subir escada (...). Era tratado alguma infecção, como candidíase, normal na gravidez sabe, ele ouvia os batimentos do nenê na barriga, (...) via o útero, se tava alto ou baixo. Esse tipo de coisa!

Embora a prevenção da saúde da gestante tenha sido considerada importante, percebe-se pelo resultado do estudo que as questões sobre o aleitamento materno ficaram em segundo plano, pois de acordo com a puérpera $A$, a abordagem a respeito deste tema só ocorreu na consulta puerperal: Controle de pressão, peso, vacina, amamentação, foi tudo falado. A amamentação foi depois (...) quando tu vai fazer revisão, daí eles falam.

Portanto, é importante estudar os temas e a maneira como estão sendo distribuídos durante as consultas de pré-natal.

Vários temas foram discutidos durante o pré-natal para o momento do parto, fase bastante delicada, em que o profissional precisa orientar a gestante quanto ao planejamento individual na escolha da maternidade, deslocamento, as necessidades para o parto e o recém-nascido, apoio familiar, do cônjuge e social. Para dar veracidade à tabela eis algumas afirmações: $A$ principal orientação que o médico me disse (...) é que não era pra ficar histérica, tipo sai gritando, (...) isso não 


\section{RECISATEC - REVISTA CIENTÍFICA SAÚDE E TECNOLOGIA ISSN 2763-8405}

\section{O PRÉ-NATAL: O OLHAR DE MULHERES GRÁVIDAS AOS CUIDADOS RECEBIDOS PELA EQUIPE DE SAÚDE Janaina Alvarenga Aragão, José Roque Junges, Luciano Silva Figueiredo, Verônica Lourdes Lima Batista Maia, Maria Conceição Portela Leal Macedo, Socorro Adriana Sousa Meneses Brandão, Leilane Sousa Dias, Rita de Kássia Leal e Silva}

ia adiantar (...), era pra ficar calma sabe, que o nenê ia nascer bem (...) (A). (...) ele disse assim, quando eu sentir dor de cinco em cinco minutos, era pra eu procurar ir pro hospital que tava perto de ganhar (...) (J). Com a respiração no caso... Cuidado de higiene com nenê, comigo (C). Ah o pósparto, relação à alimentação, pra não tomar chocolate nem café, nem comidas muito gordurosas nem apimentadas porque pode dar gases no bebê, enfim pra não toma corrente de vento, né, essas coisas normais que eles falam pra... (D).

Embora tenha ocorrido um processo educativo de preparação, percebe-se que as abordagens educativas ainda deixam a desejar, pois o depoimento da entrevistada E, primípara de 21 anos, mostra que é necessário repensar a forma como vem ocorrendo a transmissão das orientações: (...) fiquei ali esperando tudo, estando pronta pra tudo. Não teve aquela coisa de dizer vai ser assim, tu faz assim, nada. Em relação ao parto eles não falaram nada.

Assim como para as duas etapas anteriores do ciclo gestacional, as informações sobre os cuidados no pós-parto foram diversas, pois as entrevistadas relataram discussões relacionadas a consulta puérperal, alimentação materna, amamentação, cuidados com a criança em cada estação climática, com o cordão umbilical e icterícia, exame de prevenção dentre outros, comprovados com alguns depoimentos: Ah, no pós-parto, em relação à alimentação, pra não tomar chocolate nem café, nem comidas muito gordurosas, (...) e orientações em relação ao bebê, o cordãozinho umbilical (...), da pelezinha que descasca, do amarelão que pode dar (D). Na amamentação do nenê (...) até os seis meses que é o tempo apropriado né, (...) pra evitar doença. (...) (G).

Outro aspecto constatado foi o reforço na orientação quanto à necessidade da consulta puerperal conferida pelo profissional: (...) ele falou, que eu tinha que voltar depois pra fazer revisão e trazer o nenê (...) (F). Se a preocupação entre os profissionais de saúde com a consulta puerperal é observada, por que os indicadores demonstram que ela ainda é pouco realizada?

Porém, três das entrevistadas disseram não ter recebido nenhuma orientação para o pósparto, e uma delas referiu que foi com a mãe que aprendeu a conduzir-se durante essa etapa. Tal constatação é preocupante: (...) Fui saber o que era um pós-parto com as orientações da minha mãe pra ser bem sincera (...) (B).

Continuando a reflexão, questionou-se a necessidade de serem recebidas outras orientações, que talvez tenham passado despercebidas. Com base na leitura dos diálogos, pouco mais da metade das entrevistadas, sete, acharam ter recebido as informações que buscavam, mas algumas demonstraram claramente um discurso conformista: Olha! Pra mim tá bom o que ele me deu (...) (F). Outras tomaram para si a responsabilidade sobre os questionamentos: (...) não teve nenhuma orientação que eu queria (...) porque todas as dúvidas (...) eu vinha e perguntava (...) (G). E uma referiu que o tema de seu interesse talvez tenha sido explicado pelo profissional por que ela 0 inquiriu: Foi falado do parto. Ah! não sei, talvez porque eu tenha perguntado, não sei (...) (A).

Outra importante percepção constatada pelas puérperas foi sobre o dever do médico em orientar sobre a atenção ao recém-nascido: (...) eu acho que seria uma falha a falta de orientação de 


\section{RECISATEC - REVISTA CIENTÍFICA SAÚDE E TECNOLOGIA ISSN 2763-8405}

O PRÉ-NATAL: O OLHAR DE MULHERES GRÁVIDAS AOS CUIDADOS RECEBIDOS PELA EQUIPE DE SAÚDE Janaina Alvarenga Aragão, José Roque Junges, Luciano Silva Figueiredo, Verônica Lourdes Lima Batista Maia, Maria Conceição Portela Leal Macedo, Socorro Adriana Sousa Meneses Brandão, Leilane Sousa Dias, Rita de Kássia Leal e Silva

como cuidar do bebê, porque a gente vai descobrindo, e não tem como descobrir sozinha, tem que procurar recursos de outro jeito (E).

\section{Aspectos emocionais e mudanças nos vínculos afetivos: interação entre profissionais e gestantes}

Nesta categoria, analisaram-se as emoções e o modo como às orientações foram transmitidas durante o processo gestacional, se em algum momento a gestante sentiu que não foi compreendida pelo profissional, como o vínculo se construiu entre ambos e a relevância atual das consultas de pré-natal para as gestantes.

Verificou-se que todas as puérperas pareceram curiosas e ansiosas em compreender um pouco a respeito da reprodução na sua totalidade e as modificações que ela acarreta. Dentre as mais ansiosas e receosas, em primeiro lugar estavam as gestantes primíparas e as secundíparas com experiência traumática anterior: (...) a mulher quando vai ganhar bebê pela primeira vez, tu não tem noção, todo mundo fala, (...), mas quando tu chega lá tu não sabe como vai ser (...) não tem como. Então, é uma coisa inesquecível, (...) (E).

A sensação de gerar um ser é única, percepção constatada por elas mesmas, quando falam que é inesquecível. Mesmo assim, ainda há profissionais que as encaram de modo pouco sensível: (...) ele disse que era estresse da mãe, do último mês de gravidez, (...) faltava vinte três dias pro meu filho nascer e meu filho tava com problema de coração por isso eu fiz uma cesária de urgência (...), ele só me dava remédio (...) pra tomar (...) (B). Talvez aqui esteja a explicação do porquê as mulheres, mesmo as que já passaram pela primeira gestação, ainda tragam consigo sentimentos de insegurança.

Outro fato que merece questionamentos é o fato de todas as entrevistadas afirmarem que suas perguntas eram compreendidas, como observado pela entrevistada E: Fui bem atendida, bem esclarecida. Qualquer coisa que eu perguntava ele esclarecia bem direitinho. Se todas as puérperas relataram que suas perguntas eram compreendidas, e as orientações eram esclarecidas através de conversas tranquilas com 0 profissional, onde o mesmo teve a oportunidade de explicar adequadamente as mudanças anatômicas e fisiológicas da gestante e o desenvolvimento do feto intrauterino, é necessário interrogar por que ainda ocorrem situações como a entrevistada B vivenciou.

Apesar de condutas de saúde inadequadas ainda ocorrerem, felizmente todas consideraram a assistência pré-natal indispensável para o acompanhamento da evolução fetal, em primeiro lugar; e secundariamente para a avaliação da saúde materna.

De acordo com suas experiências, contexto social e visão de mundo, cada uma em particular percebeu o significado do pré-natal: Eu não imagino na época da minha mãe (...) ela não fez prénatal de nenhum de nós, (...) como é que ela ficava os nove meses (...) sem nada, eu não consigo (...). E o filho ainda sai com saúde. É Deus né e muita sorte (A). 


\title{
RECISATEC - REVISTA CIENTÍFICA SAÚDE E TECNOLOGIA ISSN 2763-8405
}

\author{
O PRÉ-NATAL: O OLHAR DE MULHERES GRÁVIDAS AOS CUIDADOS RECEBIDOS PELA EQUIPE DE SAÚDE \\ Janaina Alvarenga Aragão, José Roque Junges, Luciano Silva Figueiredo, Verônica Lourdes Lima Batista Maia, \\ Maria Conceição Portela Leal Macedo, Socorro Adriana Sousa Meneses Brandão, Leilane Sousa Dias, Rita de Kássia Leal e Silva
}

Observou-se em alguns depoimentos que a intenção na procura e continuidade do pré-natal começa com a descoberta de gerar um novo ser, de como cuidar do feto e depois do recém-nascido, pela busca de informações sobre as mudanças e aceitação nos hospitais na hora do parto e pósparto nos postos de saúde: Muito, (...) uma vez eu (...) tava sentindo uma dor e chegou uma menina, (...) não tinha feito nenhum pré-natal, (...) perguntaram pra ela que dia foi a menstruação dela, aí descobriram que ela tava com quatro (...) ela disse que não precisava de pré-natal, que todos os filhos dela ela tinha ganhado assim. Ela era índia (...) (B). É importante (...) fazer, tudo direitinho (...). E lá no hospital, eles não estão atendendo mais se tu não tem pelo menos uns quatro ou cinco prénatal, é difícil só se estiver (...) pra ganhar, porque eles brigam, eles xingam (I).

Revelaram sentirem-se mais seguras quando acompanhadas, orientadas e examinadas, para detectar alterações na sua própria saúde: (...) a gente que acompanha toda aquela rotina de exames (...), tem coisas que pega a gente de surpresa. (...) É fundamental tanto pra ti como pra o bebê, (...) fiquei bem mais tranquila, (...) da mais força (...) você saber que está tudo bem, que não vai dar problema nenhum. (...) (E).

\section{DISCUSSÃO}

\section{Onipresença do médico}

Neste estudo somente os profissionais médicos realizavam a assistência pré-natal, pois se tratava de uma unidade básica de saúde sem a ESF (Estratégia de Saúde da Família), onde a equipe central é formada por médico, enfermeira e agentes comunitários de saúde. No serviço estudado o resultado sobre o número de consultas durante o pré-natal foi maior do que as seis consultas recomendadas pela programação pré-natalista do Ministério da Saúde. (1) Este resultado foi contrário ao encontrado em outros trabalhos, como ${ }^{(16,17)}$ onde a média de consultas constatadas foi de 5,3. (18) $^{(1)}$ Destaca-se ainda a importância da necessidade de alcançar essa meta de forma homogênea, algo que ainda não foi atingido nas diversas regiões brasileiras. Homogeneidade que os autores ${ }^{(19,20)}$ relatam também não ter sido contemplada até mesmo nas unidades básicas com a ESF.

Sabe-se que há importantes discrepâncias regionais nos indicadores, sendo os melhores índices encontrados nas regiões sudeste e sul. ${ }^{(21)}$ Diante dessa reflexão, hoje, o que é mais importante? Os números dos indicadores ou a sua junção com a qualidade da assistência?

Nesta pesquisa, observou-se que as entrevistadas iniciaram o pré-natal logo no primeiro trimestre de gravidez, concordando com a literatura, a qual fala a respeito da necessidade de captação precoce das gestantes na comunidade. ${ }^{(1)}$ Este fato tem grande valor, porque produz mais estímulo e satisfação aos diferentes pares e instituições de saúde, pois é uma oportunidade a mais de somar medidas preventivas junto as gestantes.

De acordo com a fala da entrevistada $\mathrm{J}$, os cuidados ainda continuam centralizados no médico. Diante disso, percebe-se que, mesmo depois de pouco mais de duas décadas do SUS e seus avanços, o modelo biomédico ainda é marcante na cultura popular e entre os profissionais de 


\section{RECISATEC - REVISTA CIENTÍFICA SAÚDE E TECNOLOGIA ISSN 2763-8405}

\section{O PRÉ-NATAL: O OLHAR DE MULHERES GRÁVIDAS AOS CUIDADOS RECEBIDOS PELA EQUIPE DE SAÚDE Janaina Alvarenga Aragão, José Roque Junges, Luciano Silva Figueiredo, Verônica Lourdes Lima Batista Maia, Maria Conceição Portela Leal Macedo, Socorro Adriana Sousa Meneses Brandão, Leilane Sousa Dias, Rita de Kássia Leal e Silva}

saúde. (21) Porém, algumas pesquisas demonstram resultados diferentes dos achados nesta pesquisa, mostrando que a maioria dos atendimentos de pré-natal foi realizada por médicos e enfermeiros, sugerindo assim que os profissionais devem atuar em cooperação entre si, construindo laços de produtividade. ${ }^{(22,23)}$

Em relação a outros profissionais, foi averiguada no depoimento da entrevistada B a ausência do atendimento da enfermeira na unidade básica de saúde pesquisada. É importante que trabalhos futuros possam refletir melhor sobre esse achado, pois não foram assistidas por uma enfermeira e é fundamental o acompanhamento deste profissional(24). A consulta de enfermagem à gestante é um espaço educativo do qual fazem parte também seus familiares, e importante para estabelecer bom vínculo entre o profissional, a gestante e a família. ${ }^{(25)}$ Portanto, estados e municípios devem disponibilizar uma rede mínima de serviços organizados com garantia de assistência multidisciplinar e multiprofissional, de recursos físicos, materiais e tecnológicos, bem como sistemas de referência e contra referência para a atenção obstétrica e neonatal. ${ }^{(1,2)}$

Mesmo ao indicarem o médico como profissional ideal para acompanhar o ciclo gravídicopuerperal, as entrevistadas F e G observaram que os profissionais, em particular o médico, deve compreender a verdadeira vocação em saúde como compromisso ético e buscar contínua aprendizagem, sendo consciente de parar quando necessário para auto avaliar suas práticas. ${ }^{(15)}$ Para qualificar a efetividade do atendimento de saúde ao usuário a capacitação didático-pedagógica específica é um recurso que deve ser utilizado, pois possibilita a participação em estratégias e o desenvolvimento do papel profissional. ${ }^{(1,15,17)}$

A adição de outros profissionais durante a assistência de saúde gestacional foi constatada nas falas das puérperas $L$ e $A$, sendo a última, ao explicitar o pediatra, redundante, pois tal profissional pertence à mesma categoria médica. Novamente as ações de saúde continuam centradas em um único profissional. Porém, emergiu a nova compreensão da importância da nutricionista durante todo o processo para uma adequada evolução gestacional e fetal saudável, contemplando o que sugerem os autores. ${ }^{(1,23)}$

Por meio da voz das puérperas, percebe-se a fragmentação do cuidado e inadequada comunicação entre os profissionais. Talvez decorrente de uma deficiência na qualificação que inicia na academia e se perpetua na vida profissional sobre o que realmente é saúde e a importância de concretar o bem coletivo e individual. Cenário que compromete a integralidade e consequentemente a humanização no atendimento, e mostra que ainda existe a dificuldade de trabalharem equipe, fato que contraria os pressupostos das políticas públicas de saúde do SUS.

\section{Conteúdos das abordagens educativas de preparação das gestantes}

Observou-se pelos resultados que as temáticas educativas orientadas pelos profissionais às mulheres para passarem por uma experiência tranquila na gravidez estão em conformidade com as ideias do Ministério da Saúde. ${ }^{(1)}$ Contudo, a qualidade dessas informações ainda é precária, e a 


\title{
RECISATEC - REVISTA CIENTÍFICA SAÚDE E TECNOLOGIA ISSN 2763-8405
}

\author{
O PRÉ-NATAL: O OLHAR DE MULHERES GRÁVIDAS AOS CUIDADOS RECEBIDOS PELA EQUIPE DE SAÚDE \\ Janaina Alvarenga Aragão, José Roque Junges, Luciano Silva Figueiredo, Verônica Lourdes Lima Batista Maia, \\ Maria Conceição Portela Leal Macedo, Socorro Adriana Sousa Meneses Brandão, Leilane Sousa Dias, Rita de Kássia Leal e Silva
}

sistematização dos temas e dos exames solicitados é de baixa qualidade, contrariando a organização sugerida pelo Programa de Humanização do Pré-Natal e Nascimento (PHPN). ${ }^{(2,29)}$ Assim como ${ }^{(14,15)}$ neste estudo também se observou baixa qualidade na oferta das temáticas, pois as abordagens educativas, além de acontecerem individualmente, não estimularam a troca das vivências individuais, que podiam ser desenvolvidas por discussões em grupo e dramatizações, dentro ou fora da unidade de saúde.

A amamentação, tão ressaltada pelo Ministério da Saúde, não foi devidamente explorada durante o pré-natal, diferindo do resultado encontrado por ${ }^{(2,14)}$ em que as gestantes se beneficiaram dessas informações.

Alguns autores relatam bons resultados nas diferentes formas de comunicação e abordagem durante as consultas de pré-natal, mas que as mesmas são padronizadas ocorrendo do mesmo modo. ${ }^{(15,17)} \mathrm{O}$ mesmo autor asseguram que a troca de experiência (vivência) é um fator vital no atendimento em saúde, que deve ser acrescido durante todo o processo gestacional, pois aproxima os pares envolvidos.

Percebeu-se também a falta de se reafirmar a relevância da família e do companheiro, integrando-os aos cuidados durante o pré-natal, parto e pós-natal, bem como promover esse envolvimento nas discussões sobre as responsabilidades com questões de sexualidade e reprodução, resultado similar foi comprovado por outros trabalhos. ${ }^{(2,25)}$ De acordo com o P HPN, a importância da família durante o pré-natal fornece segurança e contempla tanto a integralidade quanto a humanização na assistência de saúde. Portanto, esforços devem ser concentrados na prática de educação em saúde voltada para a mulher grávida, objetivando alcançar a prevenção de complicações e óbitos precoces. ${ }^{(3)}$

\section{Aspectos emocionais e mudanças nos vínculos afetivos: interação entre profissionais e gestantes}

Existem alguns sentimentos que são mais comuns a cada trimestre da gravidez, os quais coabitam com as mulheres ao longo da gestação. Relendo os resultados da última categoria, no primeiro depoimento da entrevistada $B$, verifica-se como ainda é frágil a compreensão médica sobre os sentimentos das gestantes, principalmente dos que antecedem o parto. Esse fato merece preocupação, já que nos faz pensar nas complicações que podem acontecer no ciclo gravídicopuerperal. É no intervalo interpartal, que pode acontecer intercorrências obstétricas, reforçando que ele deve ser revisto, pois essa ação irá proteger a mulher e o feto, melhorando os resultados perinatais. $^{(2,25)}$

Pensando ainda sobre as palavras dos autores ${ }^{(1,2,25)}$, é vital assegurar o fortalecimento e 0 direito ao atendimento multidisciplinar e multiprofissional desejado pelo Ministério da Saúde. A garantia efetiva desta modalidade de atendimento tende a possibilitar maior resolução dos problemas, pois quando um profissional integrante da equipe não percebe algo irregular o seguinte pode detectar o problema e imediatamente corrigi-lo. ${ }^{(1,15,17)}$ 


\section{RECISATEC - REVISTA CIENTÍFICA SAÚDE E TECNOLOGIA ISSN 2763-8405}

\section{O PRÉ-NATAL: O OLHAR DE MULHERES GRÁVIDAS AOS CUIDADOS RECEBIDOS PELA EQUIPE DE SAÚDE Janaina Alvarenga Aragão, José Roque Junges, Luciano Silva Figueiredo, Verônica Lourdes Lima Batista Maia, Maria Conceição Portela Leal Macedo, Socorro Adriana Sousa Meneses Brandão, Leilane Sousa Dias, Rita de Kássia Leal e Silva}

Outro fato que merece reflexão é a respeito de todas as entrevistadas terem relatado que suas perguntas eram compreendidas como apontado pela entrevistada $E$, e ainda acontecerem fatos como a experiência vivida pela entrevistada B. Contexto onde se percebe mais uma quebra na harmonia que acarreta déficit na qualidade do atendimento oferecido à gestante. Portanto, mais uma vez é importante ressaltar a necessidade de fortalecer o trabalho em equipe.

Um excelente achado foi a boa imagem que as gestantes fazem das consultas de pré-natal, dos exames realizados e da importância das informações que recebem, como apontado pelas entrevistadas $A, B, I$ e E, pois quando a mulher desconfia que está grávida, muitas vezes, experiência a dúvida de prosseguir ou rejeitar a condição de gestante, decorrente do medo e da ansiedade que florescem na fase inicial.

Durante o primeiro trimestre, elas procuram os serviços de saúde também devido às mudanças físicas e fisiológicas. Por isso é necessário que os trabalhadores da área, principalmente o médico, que nesse estudo foi considerado o principal ator responsável pelo sucesso da assistência pré-natal, consigam desenvolver uma empatia e exercitem a expressão das mulheres sobre seu contexto, pois essas atitudes irão conferir tranquilidade, relação de confiança e respeito mútuo, possibilitando adequado aconselhamento e menos banalização de suas queixas. ${ }^{(1)}$ Neste estudo, constatou-se também que, embora comuns e bem conhecidas as mudanças psíquicas, ainda é pouco exercida a compreensão sobre elas pelos profissionais nas consultas de pré e pós-natal. ${ }^{(1)}$

\section{CONCLUSÃO}

A pesquisa observou que, dialogando com os usuários, é possível visualizar alguns dos entraves que dificultam as relações entre a tríade, profissionais/gestores/clientela, além de problemas de estrutura física, material e de recursos humanos na realidade atual. A aproximação da comunidade configura um ambiente rico não só para conhecer suas necessidades biológicas e fisiológicas, mas também as do cidadão comum, na sua singularidade.

Pelos depoimentos baseados na percepção das puérperas sobre a assistência pré-natal, foi possível verificar alguns problemas importantes: a) a estrutura assistencial de saúde utilizada pelos profissionais na prática não está em conformidade com as orientações contidas nos manuais de assistência pré-natal, pois ainda é possível encontrar unidades básicas de saúde onde não se disponibiliza uma equipe multiprofissional mínima; b) a precária interação entre os profissionais existentes no serviço, ou seja, ainda não conseguem realizar um trabalho articulado em ritmo de equipe, que consequentemente impossibilita o alcance de uma assistência que conjugue harmoniosamente os velhos conhecimentos já apreendidos aos novos propostos pela saúde coletiva; c) uma frágil compreensão dos profissionais, gestores e usuários sobre as políticas do SUS, mostrando a necessidade de maiores investimentos em educação permanente para todos os envolvidos; d) e em particular na assistência pré-natal, a ausência de reuniões durante o atendimento, entre as gestantes e puérperas separadamente, para promover troca de experiências 


\section{RECISATEC - REVISTA CIENTÍFICA SAÚDE E TECNOLOGIA ISSN 2763-8405}

\section{O PRÉ-NATAL: O OLHAR DE MULHERES GRÁVIDAS AOS CUIDADOS RECEBIDOS PELA EQUIPE DE SAÚDE Janaina Alvarenga Aragão, José Roque Junges, Luciano Silva Figueiredo, Verônica Lourdes Lima Batista Maia, Maria Conceição Portela Leal Macedo, Socorro Adriana Sousa Meneses Brandão, Leilane Sousa Dias, Rita de Kássia Leal e Silva}

entre si, e dessas com os profissionais de saúde para promover o atendimento integral e humanizado.

Conclui-se que, na realidade, o que o SUS deseja ainda não foi contemplado, pois os problemas encontrados comprometem seus princípios: integralidade, universalidade e equidade. Entretanto, observa-se claramente a vontade dos profissionais de saúde em concentrar seus esforços em políticas que melhorem a qualidade da saúde na atenção primária e do Brasil, país que tem sido um dos pioneiros na criação de políticas específicas para promover sua reorganização.

\section{Agradecimentos}

A todas as mulheres e profissionais que participaram desse estudo com disponibilidade e interesse. Também a FAPEPI, Fundação de Amparo à Pesquisa do Estado do Piauí pela bolsa de pós-graduação concedida e apoio para realização desta pesquisa. E por último faço uma homenagem póstuma à querida Lucilda Selli por iluminar meus pensamentos ao sugerir o estudo desta temática.

\section{REFERÊNCIAS}

1. Brasil. Pré-natal e Puerpério: atenção qualificada e humanizada-manual técnico. Brasília: Ministério da Saúde; 2005. (Série Direitos Sexuais e Direitos Reprodutivos - Caderno no 5).

2. Marque FC, Dias IMV, Azevedo L. A percepção da equipe de enfermagem sobre humanização do parto e nascimento. Esc Anna Nery R Enferm. 2006 Dez;10(3):439-47.

3. Telles JL, Borges APA. Deontologia e assistência materno-infantil. In: Schramm FR, Braz M, organizadores. Bioética e saúde: novos tempos para mulheres e crianças? Rio de Janeiro: Editora FIOCRUZ; 2005. p. 67-80.

4. Ribeiro JM, Costa NR, Pinto LFS, Silva PLB. Atenção ao pré-natal na percepção das usuárias do Sistema único de Saúde: um estudo comparativo. Caderno de Saúde Pública. 2004;20:534-545.

5. Alencar NG, Gomes LC. Avaliação da assistência pré-natal na percepção de gestantes atendidas em uma unidade com programa de saúde da família. Saúde Coletiva. 2008;04:13-17.

6. Handler A, Rosenberg D, Raube K, Lyons S. Satisfaction and use of prenatal care: their relationship among African-American women in a large managed care organization. BIRTH. 2003;30:23-30.

7. Brasil. Ministério da Saúde 2004 ano da mulher. Brasília: Ministério da Saúde; 2004.

8. Farias LM, Marques MC, Leipelt RB, Santos UEL, Souza VL, Castro JD. Acolhimento: princípios, meios e fins: o uso da ferramenta do acolhimento como instrumento para a prática integral, eqüitativa, universal e humanizada em saúde. In: Castro JD, Medeiros JE, editores. Sementes do SUS. Porto Alegre: Pallotti; 2006. p. 123-142.

9. Brasil. Conselho Nacional de Secretários de Saúde. Sistema Único de Saúde. Coleção Progestores para entender a gestão do SUS 1. Brasília: CONASS; 2007. 


\section{RECISATEC - REVISTA CIENTÍFICA SAÚDE E TECNOLOGIA ISSN 2763-8405}

O PRÉ-NATAL: O OLHAR DE MULHERES GRÁVIDAS AOS CUIDADOS RECEBIDOS PELA EQUIPE DE SAÚDE Janaina Alvarenga Aragão, José Roque Junges, Luciano Silva Figueiredo, Verônica Lourdes Lima Batista Maia, Maria Conceição Portela Leal Macedo, Socorro Adriana Sousa Meneses Brandão, Leilane Sousa Dias, Rita de Kássia Leal e Silva

10. Bauer MW, Gaskell G, Allum NC. Qualidade, quantidade e interesses do conhecimento. In: Bauer MW, Gaskell G, editores. Pesquisa qualitativa com texto, imagem e som: um manual prático. Rio de Janeiro: Vozes; 2002. p. 17-36.

11. Bauer MW, Gaskell G. Para uma prestação de contas pública: além da amostra, da fidedignidade e da validade. In: Bauer MW, Gaskell G, editores. Pesquisa qualitativa com texto, imagem e som: um manual prático. Rio de Janeiro: Vozes; 2002. p. 470-490.

12. Gaskel G. Entrevistas individuais e grupais. In: Bauer MW, Gaskell G, editores. Pesquisa qualitativa com texto, imagem e som: um manual prático. Rio de Janeiro: Vozes; 2002. p. 64-89.

13. Bardin L. Análise de conteúdo. Lisboa: Edições 70; 1977.

14. Pereira G S, Colares LGT, Carmo MGT, Soares EA. Conhecimentos maternos sobre amamentação entre puérperas inscritas em programa de pré-natal. Caderno de Saúde Pública. 2000;16:457-466.

15. Ayres JRCM. Sujeito, intersubjetividade e práticas de saúde. Ciência \& Saúde Coletiva. $2001 ; 6: 63-72$.

16. Silveira DS, Santos IS, Costa JSD. Atenção pré-natal na rede básica: uma avaliação da estrutura e do processo. Caderno de Saúde Pública. 2001;17:131-39.

17. Rocha AC, Andrade GS. Atenção da equipe de enfermagem durante o pré-natal: percepção das gestantes atendidas na Rede Básica de Itapuranga - GO em diferentes contextos sociais. Revista Enfermagem Contemporânea. 2017 Abril; 6(1):30-41.

18. Leal MDC, Esteves-Pereira AP, Viellas EF, Domingues RMSM, Gama SGND. Assistência prénatal na rede pública do Brasil. Revista de Saúde Pública. 2020;54(08).

19. César JA, Matijasevich A, Santos IS, Barros AJD, Costa JSD, Barros FC, Victora CG. The use of maternal and child health services in three population-based cohorts in Southern Brazil, 1982-2004. Caderno de Saúde Pública. 2008;24:427-436.

20. Serruya SJ, Lago TG, Cecatti JG. Avaliação preliminar do programa de humanização no pré-natal e nascimento no Brasil. Revista Brasileira de Ginecologia e Obstetrícia. 2004a;26:517-525.

21. Nunes ED. Saúde coletiva: uma história recente de um passado remoto. In: Campos GWS, Minayo MCS, Akerman M, Drumond Júnior M, Carvalho YM, organizadores. Tratado de saúde coletiva. São Paulo: Hucitec; 2006. p. 19-40.

22. Bonfim EG. A violência doméstica contra a mulher na perspectiva da atenção pré-natal pública [dissertação]. Porto Alegre: Escola de Enfermagem da Universidade Federal do Rio Grande do Sul; 2008.

23. OMS. Renovação da estratégia de saúde para todos: princípios orientadores e tópicos essenciais para a elaboração de uma política de eqüidade, solidariedade e saúde. Rio de Janeiro: Fiocruz; 1996.

24. Vale CL, Brito RG, Silva AA, Santiago RF, Nery IS. Percepção de gestantes sobre o pré-natal. Revista Interdisciplinar. 2018;10(4):39-49.

25. Landerdahl MC, Ressel LB, Martins FB, Cabra FB, Gonçalves MO. A percepção de mulheres sobre atenção pré-natal em uma unidade básica de saúde. Escola Anna Nery Revista Enfermagem. 2007;11:105-111. 